\title{
Práticas seguradoras na história de diferentes campos de atividade humana e na história da educação matemática escolar brasileira
}

\section{Rafael Mora Camolez*}

\begin{abstract}
Resumo
A pesquisa que realizamos investigou diferentes aspectos relacionados a práticas de seguro. Inicialmente,fizemos uma investigação historiográfica a fim de identificarmos rastros de práticas seguradoras que teriam sido realizadas em diferentes campos de atividade humana ao longo do tempo. Em seguida, procuramos investigar, na história, o surgimento de teorias de probabilidade e estatística com o propósito de identificar possíveis efeitos - diretos ou indiretos - desses saberes sobre as práticas seguradoras. Investigamos, particularmente, algumas práticas normativas de cálculo de preços de seguros de veículos automotivos e, por fim, analisando programas de ensino, documentos oficiais e livros didáticos destinados à escolarização secundária, desde o final do século 19, procurando investigar a presença de possíveis rastros de práticas seguradoras na história da educação matemática brasileira.
\end{abstract}

\section{Palavras-chave:}

Seguros, Educação Matemática, Estatística e Probabilidade.

\section{Introdução}

O objetivo central da pesquisa foi o de investigar rastros de práticas seguradoras - realizadas em diferentes campos de atividade humana ao longo da história - na história da educação matemática brasileira. Para contemplar tal propósito, outros aspectos mediadores relativos a práticas seguradoras foram também investigados: 1) a constituição de tais práticas na história de diferentes campos de atividade humana; 2) a constituição histórica de teorias normativas probabilísticas e estatísticas; 3) a constituição histórica da Ciência Atuária e da profissão do atuário 4) práticas normativas de cálculo de preços de seguros de veículos automotivos que vêm sendo realizadas nos campos de atividade financeira e comercial na atualidade.

\section{Resultados e Discussão}

Inicialmente, realizamos investigação para identificar rastros de práticas seguradoras na história diferentes campos de atividade humana. Encontramos os primeiros registros de atividades que remetem a práticas seguradoras no Código de Hamurabi, por volta de 1700 a.C. Na Antiguidade, foi o campo comercial de atividade humana, sobretudo o comércio marítimo, o responsável pela constituição e transmissão de tais práticas de um povo a outro. Exemplo disso foi a prática seguradora da mutualização, que circulou da ilha de Rhodes para a Roma antiga. No mundo ocidental, as práticas seguradoras alcançaram maior credibilidade voltadas ao financiamento de embarcações, após o ano 1000 d.C., sobretudo nas cidades italianas de Gênova e Veneza, duas grandes potências marítimas e centros comerciais da época. Foi o momento de início da formação de grandes empresas seguradoras européias, tais como a Lloyd's de Londres. No Brasil, o comercio de seguros foi iniciado em $1808 \mathrm{com}$ a vinda da família real, que fundou a primeira seguradora do país, a Companhia de Seguros Boa-Fé. A legislação sobre o mercado de seguros foi desenvolvida a partir do século XIX, bem como a constituição de empresas que regulam e formam o SNSP - Sistema Nacional de Seguros Privados. Numa outra entrada da pesquisa, investigamos o surgimento de teorias de probabilidade e estatística com o propósito de identificar efeitos desses estudos sobre as práticas seguradoras. $O$ início das tabulações estatísticas - com John Graunt em Londres -, bem como o desenvolvimento de teorias matemáticas de probabilidade, desafiaram de modo convincente concepções místicas ou céticas do imprevisível - visto por Aristóteles como um conjunto de eventos inacessíveis ao conhecimento científico -, dando início a um conjunto crescente de práticas de controle normativo (matemático) de fenômenos casuais, o que levou ao surgimento, no século XX, da Ciência Atuária. Investigamos também como é feita, atualmente, a normatização de práticas seguradoras relativas a cálculos de precificação de seguros de veículos automotivos, para o que a utilização de teorias de probabilidade e análise estatística se mostrou imprescindível para um melhor controle preditivo de sinistros. Por fim, este conjunto de investigações mediou a nossa investigação central, cujo propósito foi o de identificar rastros de práticas seguradoras nos currículos escolares brasileiros.

\section{Conclusões}

Desde a antiguidade, diferentes tipos de práticas seguradoras foram realizadas em diferentes campos de atividade humana. Até o período renascentista, tais práticas eram realizadas independentemente de conhecimentos relativos a probabilidade e análises estatísticas de dados. O êxito preditivo resultante de tais estudos que conduziram à normatização matemática de tais práticas levou ao surgimento da Ciência Atuária e da profissão do atuário. No âmbito escolar, rastros de práticas seguradoras mostraram-se presentes, mais diretamente, em livros de Matemática Comercial e Financeira, anteriores à Reforma Francisco Campos (1932). Em reformas posteriores da educação básica, rastros diretos de práticas seguradoras desapareceram dos programas de ensino e dos manuais didáticos. Entretanto, acusamos rastros indiretos de tais práticas em tópicos dos programas e dos livros, tais como: análise combinatória, estudo das probabilidades e de alguns conceitos estatísticos, desvinculados dos problemas vitais que instituíram e constituíram as práticas seguradoras. 